\title{
Customer Relationship Management Practices: What Effect of Culture in the B to B Agri-Food Context?
}

\author{
Laila Ouhna $^{1^{*} \quad \text { Meryem Alaoui Amine }}{ }^{2}$ \\ 1.Faculty of Juridical, Economic and Social Sciences, Ibn Zohr University, Road $N^{\circ} 10$ Azrou, Ait Melloul, \\ Agadir, Morocco \\ 2.Faculty of Juridical, Economic and Social Sciences, Mohamed 5 University, Road Outa Hssain, Sala Al Jadida \\ B.P. 5295 Salé, Morocco
}

\begin{abstract}
The present research aims to investigate Customer Relationship Management practices in the Business to Business context and in particular in relationships between producers and distributors. A qualitative study was carried out in Moroccan agri-food companies to explain influence of culture on CRM practices in this context.The results of this study suggest the importance of relationships practices in agri-food loyalty strategies. However, to maintain distributors' loyalty, agri-food companies neglected the role of dependence. This result is justified by culture in the agri-food context of the Souss Massa region in Morocco.
\end{abstract}

Keywords: Agri-food, B to B relationships, CRM, culture, dependence.

DOI: $10.7176 / \mathrm{EJBM} / 11-8-08$

Publication date:March $31^{\text {st }} 2019$

\section{Introduction}

The food retailing industry in Morocco has expanded rapidly. Recently, in 2017, Morocco's food retail market represents $12 \%$ of Gross Domestic Product. In Casablanca-Rabat corridor, 50\% of all modern retailers are concentrated (USDA, 2017). In parallel, in Souss Massa region all modern food retailers are installed. We count Marjane Holding (Marjane and Acima) and Label'Vie (Carrefour, Carrefour Market, and Atacadao) and other notables including Ynna (Aswak Salam).

On the other hand, in the same Moroccan region a large agri-food industry is developed. These industries are worry about maintaining good relationships with their distributors. There are oriented to relational marketing to retain their distributors.

The evolution toward relational exchange and in particular toward relational marketing has highlighted the role of defensive marketing in managing inter-organizational relationships. It is in this context that the CRM is perfectly positioned to defend the market share of companies by maintaining good and lasting relationships.

In parallel, the concept of dependence is widely used in marketing especially by relational literature (Frazier, 1983). Several researchers have considered dependence as a tool for customer loyalty and retention (Benavent \& Meyer-Waarden, 2004). They use it as a tool to develop exit barriers for customers. Firms search to increase perceived risk and costs of change to customers in order to prevent them from thinking about changing supplier.

Thus, dependence, as a defensive strategy tool, is adopted by various loyalty programs generally in the services context. Nevertheless, it is appreciated differently depending on the field of study and the culture of the target audience.

It is in this context that the present research aims to evaluate the effect of Moroccan agri food industries culture on Inter-organizational Customer Relations Management ICRM and particularly to explain the place of dependence on relationships between producers and distributors.

In response to these objectives, we conducted a qualitative study on agri-food companies and relationships with distributors.

The paper first presents a brief literature review of focal constructs which is followed by a method, findings and discussion.

Finally, the implications and contributions are explored.

\section{Conceptual background}

\subsection{Customer Relationship Management CRM}

Customer Relationship Management represents an effective tool for managing and maintaining exchange relationships that implies a shift from transaction-based marketing to a relational mode (Osarenkhoe \& Bennani, 2007). The CRM is then a set of activities that focuses on the customer relationship and not the sales transaction. It is also considered as a corporate strategy. Companies seek to implement it to increase profits by ensuring customer satisfaction. Indeed, CRM strategy should be consistent with the organizational effectiveness of the company.

The CRM aims to keep customers rather acquiring new ones. It represents a process for customer identification, relationship building and improving the image of the company and its products (Jallat, Stevens \& 
Volle, 2007).

The ultimate strategic goal of CRM is to achieve some intimacy with customers (Jallat et al., 2007). The two parties of this relationship, customer and supplier, will benefit from knowing each other better, cooperating and developing a certain level of trust and mutual commitment. In fact, we argue that CRM represents a complex combination of business and technology factors. So, these strategies must be formulated accordingly (Zineldin, 2006).

In the same strategic perspective, CRM is a useful tool for identifying customers groups. It helps companies decide which customers they want to keep and retain. This targeting operation is not carried out through mass media because these are impersonal and do not suit all types of customers (Winer, 2001). In this sense, Peppers and Rogers (2004) favor direct communication with selected customers through targeted approaches rather than using the media.

For this purpose, the IDIC (Identification, Differentiation, Interaction and Customization) approach proposed by Peppers, Rogers \& Dorf (1999) represent a practical CRM tool for businesses. This approach is based on four steps:

The first step is to identify the customers and decide on which customers should be retained.

The second step involves differentiating the customers. In general, there are different types of customers; they have different needs which need to be satisfied. These must be identified and those who are judged to be the most useful to the company must be identified and targeted.

The third step is interaction with the chosen customers. This interaction is based on continuous communication with the category of clients selected, with the dialog adapted to this category of customers.

The fourth step of the IDIC approach is based on the personalization of the product offered to meet the needs of each selected client. It relies on the adaptation of certain aspects of the company's behavior to meet the specific needs expressed by each customer. This customization operation locks the client into a learning relationship.

Current CRM techniques have evolved with the development of relationship marketing. The focus is on improving customer loyalty through effective customer relationship management (Zineldin, 2006).

Therefore, the company must develop a culture of customer relationship management. This ensures its efficiency, success and profitability. However, the implementation of customer relationship management also requires a reflection on the overall organization of the company and the nature of its relationships with its customers.

In the case of retail customers, the relationship is rather a partnership between two organizations. This type of inter-organizational relationship tends, in most cases, toward the search for a lasting and profitable relationship. Relational marketing literature has linked CRM with different relational variables. Among these relational variables, dependence represents a tool of CRM (Benavent \& Meyer-Waarden, 2004).

\subsection{Dependence as tool in CRM strategy}

In an environment characterized by uncertainty, managing distributor-producer relationships needs strategic decision. Indeed, each party tries to develop more stable relationships and the dependence can determine the power of each party within these relationships. In this context, resource dependence theory based on the theory of social exchange deals with governance between firms as a strategic response to conditions of uncertainty and dependence (Emerson, 1962; Pfeffer \& Salancik, 1978).

In inter-organizational relationships, the concept of dependence refers to the need for a firm to maintain an exchange relationship in order to achieve the desired goals (Frazier, 1983); this is considered an aspect of power (Emerson, 1962).In accordance with rational theory, inter-organizational relationships give importance to the power aspect. Indeed, this aspect is strongly sought by companies to ensure the dependence of their customers on their offers.

The correlation between power and dependence has been confirmed by the literature (Frazier, 1983; Kale, 1986; Pfeffer \& Salancik, 1978; Heide, 1994). Pfeffer and Salancik (1978) state that "when the net exchange between two organizations is asymmetrical, a "net power" arises from the least dependent organization on the other. This power can be used to try to influence or constrain the most dependent organization" (p.53). These two authors identify three critical factors that make it possible to assess an organization's dependence on others. These factors are, the importance of the resource to the dependent organization, the exclusiveness or otherwise of a group of interest that can provide the resource, and the extent of power of a group of interest over the resource.

The inability to control flows of resources develops some uncertainty within the company, which is trying to reduce this uncertainty and then begins to structure its relations by creating formal or semi-formal links with other companies.

The concept of inter-organizational dependence has been used in the marketing literature with different visions. Indeed, some authors consider it to be a factor of rationality.

For Emerson (1962), the dependence between exchange partners is related to the investment and the goals sought by the relationship. So, authors give importance to power and the material aspect of the exchange 
relationship (Pfeffer \& Salancik, 1978).

Other authors link the dependence of one party to another on the value of the exchange object and its unique specificity. Indeed, an object that does not have many alternatives will be more sought after and dependence is then launched (Heide \& John, 1988).

Thus, an organization's dependency is defined as the result of the need for the organization to maintain the relationship in order to achieve specific goals (Frazier, 1983; Ganesan, 1994).

In the context of producer-distributor relationships, a distributor's dependence on the producer is linked to the results obtained by the customer in his relationship with the supplier as well as the value of the exchanges (ElAnsary \& Stern, 1972).

According to the theoretical analysis, dependence can has a place in the functioning of CRM distributors in western culture. Nevertheless, this place is related to the context of the study and especially to the culture of exchange relations (Abbad, Paché, \& Bonet Fernandez, 2012).

\subsection{Culture as moderator of inter-organizational CRM}

Organizational culture refers to the collection of values and norms shared by people in an organization and that control how they interact with each other and with stakeholders both in an organization and outside the organization (Schein, 2010). It affects attitudes toward external partners as well as overall performance. Culture governs "what a business is, how it allocates resources, its organization, its structure, the systems it uses, the people it hires, the fit between jobs and people, the results that it recognizes and rewards what it defines as problems and opportunities, and how it deals with them" (Petrock, 1990: 66). Although there is no consensus on the definition of culture, researchers believe that culture is essential for the success of any organization.

Organizational culture is of crucial importance in the management of relations between a company and its partners as it influences the attitudes and commitment of all members of the company in the establishment and development of these relationships.

Hewett, Money \& Sharma (2002) empirically studied customer-supplier industrial relationships and explored the impact of customer perception of the quality of these relationships on redemption intentions. They found that there is a positive and significant relationship between the quality of the customer-supplier relationship (especially the level of trust and commitment between the two parties) and the redemption intentions. However, this relationship is moderated by the organizational culture of the clients. In this context, the authors explained that a good understanding of the culture of purchasing firms can allow a company to identify buyers with a greater potential for redemption.

Management must have a strategy to ensure the retention of customers including how to determine the potentially most profitable or most loyal buyers, and then develop programs to strengthen relationships with these customers.

On the other hand, Jarratt \& O'Neill (2002) pointed out that in the B to B context the evaluation of organization culture is the critical starting point for any development relationships.

Furthermore, cultural values such as flexibility, innovation, communication, and consultation are considered essential to support relationship management and improve relationship performance.

The authors add that the cultural value of "organizational openness" is an essential ingredient for creating lasting relationships based on trust and commitment.

Therefore, understanding and assessing the cultural values of organizations is important to ensure the compatibility of this culture with the effectiveness of relationship management practices.

Similarly, Yanga, Chaob, Liuc, Chend (2014) carried out an empirical study in Taiwanese companies on the impact of organizational culture on collaborative business relationships, specifically the quality of the relationship and the proximity of the relationship. They demonstrated that organizational culture is one of the determinants of collaborative relationships.

In Morocco, like Japanese and Chinese context, channel relationships are stable and focused on long term dealings differently to Western context (Fahy \& Taguchi, 1995; Miyamoto \& Rexha, 2004). Thus, long term orientation became socially institutionalized norms.

American studies explain that the dependence of retailers on suppliers is largely driven by economic and role performance concerns.

However, in other context characterized by social culture as Japanese and Moroccan retailer-supplier relationships, the dependence of retailers on suppliers was not driven by supplier role performance (Sternquist et al., 1995, 2000), but it is result of a long-term orientation norm in culture (Chung, Sternquist \& Chen, 2007).

Although, the interaction of buyers with their suppliers is a business activity, it is still governed by interpersonal cultural dimensions (Chung, 2007). 


\section{Method}

\subsection{Data collection}

To explore CRM strategies, a qualitative study was conducted on agri-food companies in the Souss Massa region in Morocco. Indeed, the functionalist perspective of this research requires the use of the interview tool in the qualitative study (Giordano, 2003). The exploratory nature of the research conducted explains the lack of knowledge on the subject in order to directly use harsher methods such as the questionnaire. As a result, the interview will explain the place of dependence in CRM strategies adopted by agri-food companies toward their distributor customers and how culture affects these CRM practices.

Interviews were conducted with those responsible for marketing in ten agri-food companies in several industries (fruit and vegetable packaging house, dairy industry, fish industry). Data were collected via individual semi-directive interviews in order to have personal contact with the individual and to make sure that the questions were fully understood. The selection of respondent firms was not random. In fact, in qualitative research, the goal is to have a small sample with a diversity of views (Giordano, 2003). We seek rich content, diversity and quality (Evrard, Pras \& Roux, 2003). For this reason, accessing respondents was a difficult step in our research.

The interview guide used in the study explores the relationship between producer and distributor and includes a set of themes regarding the CRM strategy used by agri-food companies. The first theme tackles general information about the activity of the company and its distribution policy. The second theme seeks to evaluate the formalization of the CRM strategy. The third theme concerns dependence as a CRM tool used by the company.

\subsection{Data analysis}

We collected data by using "audio recording" and note taking during the interviews. The use of an audio recorder allowed the integrity of the opinions expressed to be preserved, thus ensuring that data was exhaustive and discursive, without worrying about the risk of missing information (Thietart, 1999). Only one interviewee did not agree to be recorded, but he was very cooperative and helped us to take notes.

After collecting data, we transcribed the interviews in full in order to analyze them correctly. This then allowed us to make the thematic analysis. The text of the transcribed interviews was devised, and these units were then combined as defined themes in categories.

According to Bardin (1993) cited in (Quivy \& Campenhoudt, 2011), three methods of content analysis exist: thematic analysis, formal analysis and structural analysis. In our qualitative study, we used the thematic analysis method, and principally, a categorical thematic analysis. This method consists of evaluating and comparing the frequencies of certain characteristics previously grouped into categories (Quivy \& Campenhoudt, 2011). In addition, an analysis of the evaluation was able to facilitate the interpretation of results.

\section{Findings}

The literature review helped us to interpret the results of the qualitative study.

A first theme was to introduce the discussion and measure the degree of formalization of the CRM strategy in Moroccan firms.

\subsection{Distribution strategy}

In the agri-food industry, companies often adopt intensive distribution through the use of retailers, and for some companies, wholesalers. In addition, they distribute their products in all hyper markets available in Morocco such as "Marjane", "ATACADAO”, "Carrefour Market", "Acima” and "Aswak assalam”.

\subsection{CRM strategy}

4.2.1. Evaluation of distributor relationships

The companies surveyed evaluate the nature of the relationships with their distributor customers through buy-back, re-cooperation and the renewal of contracts.

All the companies surveyed confirmed that they practice CRM in an informal way. They do not adopt a loyalty program. This is explained by the specificity of the agri-food sector. Nevertheless, one company did have experience in implementing a customer loyalty program. This program was evaluated as ineffective and was stopped. The company explained its ineffectiveness by the fact that retail customers do not want to depend on just one program.

"Adopting a loyalty program is not beneficial for us, the specificity of our activity does not allow, and even our customers do not appreciate it " representative of the drink's industry.

4.2.2 Steps of CRM

The CRM steps, based on the IDIC approach (Peppers, Rogers \& Dorf, 1999) are:

Customer identification: The Company distinguishes the customers it wishes to retain. According to our study, these customers are determined according to different criteria:

Purchase volume, customer solvency, seriousness, commitment and responsiveness. "Eight to ten of our customers 
are entitled to unlimited products with exceptional conditions. These eight customers are classified according to: the tonnage purchased, their frequency, their solvency and compliance with their commitments" Fruit and vegetable packaging company.

The distinction between customers: Agri-food companies distinguish between identified customers and then concentrate their efforts on gaining the most benefits from those deemed most valuable.

Indeed, they differentiate between them by offering different payment facilities and by negotiating the terms of the contract.

According to the study, "This is mainly a negotiated contract. We draw up a different contract for each client; if we want to retain a particular client, the contract might contain clauses on payment facilities. We try to increase the value shared by the customer and the supplier: Radius packaging actions, activate a sandwich radius (offer a free drink with each sandwich); according to the occasion: birthday shop, Ramadan, summer, sports activities..." representative of a beverage company.

Interaction with chosen customers: The most powerful tool here is the interactive communication with the category of selected customers. In the case of the agri-food companies surveyed, they maintain continuous contact with distributors. It is an interactive communication to ensure continuous satisfaction.

Personalization of the offer: The offer is based on the adaptation of certain aspects of the behavior of the company to meet the specific needs of individual customers or distributors.

This customization operation locks the client into a learning relationship. "The value of learning is concretized especially on the help that one offers for certain customers in order to manage their orders". Vegetable packaging company.

4.2.3. Distributor CRM Tools: Place of Dependence

According to interviewees' responses, engagement is an important tool for maintaining a relationship. Businesses talk mostly about mutual commitment.

"Mutual commitment increases loyalty and relationship quality" Cheese company representative. In addition, the interviewees specified that the determinants of commitment are: trust, seriousness, repute, and positive word of mouth, but satisfaction is also a strong determinant.

At the same time, dependency as a CRM tool was very badly perceived by our interviewees. They totally refuse to accept it as a CRM variable. They prefer to talk about cooperation.

"Dependence is not profitable, it is dangerous. It presents a risk of hostile customers, because according to the culture of our customers, dependence disturbs them, and furthermore, the company will not be motivated to develop good relations, which constitute the key of success". Beverage company representative.

"For us, a high dependence is not beneficial". Vegetable packing station representative.

We note that agri-food companies consider that dependence as a tool could potentially lead to the risk of a loss of market share.

With regard to CRM for large distribution, agri-food companies do not give any consideration to dependency. "We cannot imagine how a large surface can be dependent on the company except for product $X$ where the brand imposes it. But for other products... It's not possible at all'. Beverage company representative.

According to the results of our study, agri-food companies explain that the culture of retail customers as well as company culture consider that dependence has a negative effect on the continuation of relationships.

"A customer never accepts being dependent. He tries to pretend and resist this position... The solution is cooperation." Fruit packing station representative.

4.2.4. Culture as an explanatory variable of CRM distributors

Agri-food companies consider culture to be a determining factor in the rejection of dependence in CRM dealer practices:

The non-formalization of CRM practices is explained by the rejection of dependency: "We will never set up a loyalty program because it's embarrassing. The company would be dependent on this program.... . Furthermore, the programs are not effective because they are simple tools that a competitor can easily destroy. It is a special tool which cannot be adapted to the B to B context and especially in agri-food companies. It also depends on the culture of the customer; he does not want to be seen in a weak position. He likes freedom." Beverage company representative.

\subsection{Customer culture}

"We are very familiar with the culture of our customers: The customer does not like monopoly. He does not feel comfortable about dependence... The company seeks to satisfy customers and not make them dependent on promotional actions ...."

Culture focusing relational values: "The relationship orientation is the culture of our agri-food group... The continuation of relationships is very important. It is explained by the human character. For example, if a customer has difficult paying, we can allow it. We cooperate. The company considers the relationship to be important, it allows agents to facilitate the customers..." 


\section{Discussion}

According to the thematic analysis, Moroccan agri-food companies adopt non-formal CRM strategies. They do not favor the use of loyalty programs. This result is explained by the culture of the companies which consider that the program imposes a negative dependence. Indeed, they do not accept being dependent on any type of loyalty program.

The CRM practices of agri-food companies are regrouped in four steps. Identification, differentiation, interaction and personalization.

For the first stage -identification - the agri-food companies interviewed identify the customers to be selected mainly by the criterion of respect for the commitment.

Subsequently, these companies differentiate between their distribution customers essentially by relational advantages.

We find that dependency is perceived as an inefficient tool in the strategies of CRM distributors, or even as a dangerous tool by some companies. In fact, Moroccan agri-food companies talk about its negative effect on maintaining relationships with retail customers. This result is explained by the culture of the companies operating in the Moroccan agro-food sector, and particularly in the region of Souss Massa, where a relational culture predominates. They give particular importance to the values they share. Indeed, organizational culture, through its assumptions, values, norms and symbols determines how members of an organization perceive and interpret reality within and outside their organization, as well as the way they behave in this reality. (Janićijević, 2011).

Our results join Abbad's research $(2006,2007)$. Abbad dealt with the relationships between suppliers and distributors in the Moroccan agri-food sector. His results explain that dependence has a negative effect on maintaining lasting relationships with distributors (Abbad, 2007).

The work of Janićijević, (2012), also supports the results of our research. Moreover, by analyzing the impact of organizational culture on organizational change strategy choices, Janićijević has emphasized that the culture of power and family culture influence the choice of dependency relationships, which the author describes as the basis of "the coercive power strategy".

Indeed, this strategy involves the perspective of voluntarism human action, imposing a vision of the world in which people are free agents who can independently choose their actions.

Fukuyama (1995) argues that the deepest level of culture includes phenomena such as family structure, religion, moral values, ethnic consciousness, "being civic-minded", and particular historical traditions. These elements give rise to different forms of cultures by nations.

In the case of the Souss Massa region in Morocco, agri-food actors are generally farmers who often have ethnic origins. These are characterized by great sociability which influences the exchange relationships.

So, the rejection of dependence as a CRM tool in agri-business in Morocco is explained by the cultural specificity of the context of the study. In fact, agri-food operators are generally farmers with a culture that favors freedom of action.

Our explanation of this phenomenon can also be based on different perceptions of loyalty between the supplier and the customer.

Indeed, loyalty has been defined previously as a set of actions aimed at increasing the consumer's dependence on the product, or a brand (Crié, 2002).

While the desired loyalty is defined as "A set of elements aimed at retaining the consumer in complete freedom, until his perfect loyalty" (Lehu, 2003). Lehu insists on freedom of action. Customers demand a climate of total freedom in their loyalty behaviors.

\section{Conclusion and implications}

In this paper we have tried to study the place of dependence in the management of inter-organizational customer relations in the agri-food industry and the effect of culture on this CRM practices.

Indeed, the work of Pfeffer \& Salancik (1978) pays particular attention to the context of exchange, the motivations of actors and actions. Moreover, dependence and uncertainty are approached as explanatory variables of inter-organizational relations. These elements can be important for the definition of a CRM strategy in the interorganizational framework.

However, the results of our qualitative exploratory study of agri-businesses revealed that because of the culture of these companies, they are adopting unconventional CRM strategies and that loyalty programs are addictive. Customers do not appreciate this addiction. They rebel when they encounter it.

Our research presents a number of theoretical and empirical contributions. At the theoretical level, our results indicate that the theory of resource dependence is judged to be incomplete in order to frame inter-organizational relationships. It offers only a macroscopic view of the mechanisms that can be used to govern these relationships (Heide, 1994). In addition, the strategies proposed to manage uncertainty and dependence vary widely in terms of the demands placed on firms and the benefits they bring (Scott, 2003) and our research contribute to literature by developing the role of culture as moderator of relational model, in particularly, to moderate the role of dependence 
in CRM strategy.

At the empirical level, our research highlights the importance of culture in managing inter-organizational relationships. In the B to B context, companies consider the strategic exclusivity of their offer to be important. However, in a culture of important social values, customers reject exchange relationships based on dependence in favor of exchange relationships based on trust and mutual commitment. So, relational variables are very important in agri-food inter-organizational exchange in the Souss Massa region.

\section{References}

Abbad, H. (2007). Stratégies de référencement des PME industrielles et critères logistiques: le cas de la grande distribution au Maroc. In Working Paper de l'Institut d'Administration des Entreprises (IAE) d'Aix-enProvence.

Abbad, H., Paché, G., \& Bonet Fernandez, D. (2012). Peut-on désormais parler d'engagement du distributeur dans la relation avec l'industriel? Management international/International Management/Gestiòn Internacional, 16(4), 103-116.

Benavent, C., \& Meyer-Waarden, L. (2004). Programmes de fidélisation: Stratégies et pratiques. Revue française du marketing, 2/5(197), 95 .

Chung, J. E., Sternquist, B., \& Chen, Z. (2008). Japanese retail-buyer-supplier relationships: does performance matter?. Asia Pacific Journal of Marketing and Logistics, 20(1), 55-75. https://doi.org/10.1108/13555850810844878.

Daft, R.L. (2004). Organization Theory and Design. (8th Eds.). Thomson, London.

Des Garets, V. (2005). La gestion de la relation client dans la banque. Cahiers de recherche de CERMAT, (18-05), 120.

Donada, C., \& Nogatchewsky, G. (2007). La confiance dans les relations interentreprises. Revue française de gestion, 175(6), 111-124. https://doi.org/10.3166/rfg.175.111-124.

El-Ansary, A. I., \& Stern, L. W. (1972). Power Measurement in the Distribution Channel. Journal of Marketing Research, 9(1), 47-52. https://doi.org/10.1177/002224377200900110.

Emerson, R. (1962). Power-dependance relations. Americain sociological review, 27(1), 31-41.

Evrard, Y., Pras, B., \& Roux, E. (2003). Market - Etudes et recherches en marketing. Nathan, Paris.

Fahy, J., \& Taguchi, F. (1995). Reassessing the Japanese distribution system. MIT Sloan Management Review, $36(2), 49$

Frazier, G. L. (1983). Inter-organizational exchange behavior in marketing channels: A broadened perspective. The Journal of Marketing, 68-78. https://doi.org/10.2307/1251400.

Fukuyama, F. (1995). I. The Primacy of Culture. Journal of Democracy, 6(1), 7-14. https://doi.org/10.1353/jod.1995.0007.

Ganesan, S. (1994). Determinants of long-term orientation in buyer-seller relationships. the Journal of Marketing, 1-19. https://doi.org/10.2307/1252265.

Giordano, Y. (2003). Conduire un projet de recherche. Une perspective qualitative (Management et société). France.

Hewett, K., Money, R. B., \& Sharma, S. (2002). An exploration of the moderating role of buyer corporate culture in industrial buyer-seller relationships. Journal of the Academy of Marketing Science, 30(3), 229-239. https://doi.org/10.1177/0092070302303004.

Ke, W., Wei, K.K. (2008) Organizational culture and leadership in ERP implementation. Decision Support Systems, 45(2), 208-218. https://doi.org/10.1016/j.dss.2007.02.002.

Miyamoto, T., \& Rexha, N. (2004). Determinants of three facets of customer trust: A marketing model of Japanese buyer-supplier relationship. Journal of Business Research, 57(3), 312-319. https://doi.org/10.1016/S01482963(01)00327-7.

Iglesias O., Sauquet A. and Montaña J. (2011). The role of corporate culture in relationship marketing. European Journal of Marketing. Vol. 45 No. 4, 2011 pp. 631-650. https://doi.org/10.1108/03090561111111361.

Jallat, F., Stevens, E., \& Volle, P. (2007). Gestion de la relation client, Ed Peelen (2ème). Paris: Pearson Education.

Janićijević, N. (2011). Methodological Approaches in the Research of Organizational Culture. Economic Annals, 46 (189), pp. 69-100. https://doi.org/10.2298/EKA1189069J.

Janićijević, N. (2012), the influence of organizational culture on organizational preferences towards the choice of organizational change strategy, Economic Annals, LVII(193), pp. 25-51. https://doi.org/10.2298/EKA1293025J.

Jarratt, D., \& O'Neill, G. (2002). The Effect of Organizational Culture on Business-to- Business Relationship Management Practice and Performance. Australasian Marketing Journal, 10(3), 21-40. https://doi.org/10.1016/S1441-3582(02)70156-0.

Lefébure, R., \& Venturi, G. (2004). Gestion de la relation client. Editions Eyrolles.

Lehu, J.-M. (2003). Stratégies de fidélisation (Editions d'Organisation). Paris. 
Macneil, I. R. (1980). The new social contract: An inquiry into modern contractual relations. Yale university press.

Meyer-Waarden, L. (2004). La fidélisation client: Stratégies, pratiques et efficacité des outils du marketing traditionnel (Vuibert). Paris.

Morgan, R. M., \& Hunt, S. D. (1994). The commitment-trust theory of relationship marketing. the journal of marketing, 20-38. https://doi.org/10.2307/1252308.

Peppers, D., \& Rogers, M. (2004). Managing customer relationships: a strategic framework. Wiley.

Peppers, D., Rogers, M., \& Dorf, B. (1999). Is your company ready for one-to-one marketing. Harvard Business Review, 77(1), 151-160.

Pfeffer, J., \& Salancik, G. (1978). Chapter 3:Social control of organizations. In the external control of organizations a Resource Dependence Perspective (American Book-St\&ford Press, Inc.). New york.

Quivy, R., \& Campenhoudt, L. van. (2011). Manuel de recherche en sciences sociales; avec la collaboration de Jacques Marquet.

Schein, E. (2010). Organizational Culture and Leadership, Edition: Jossey-Bass Fourth, USA, Edition,

Stanley F. Slater \& Eric M. Olson \& Carol Finnegan, (2011), Business strategy, marketing organization culture, and performance, Marketing Letters, 22:227-242.

United States Departement of Agriculture (2017). Report detailing retaliation to U.S 232 and 301, Global Agriculture Information Network Online.

Yanga,M-H ,Chaob H-Y , Liuc S- C , Chend H. L (2014), Exploring the Determinants and Effects of Relationships in Collaborative Commerce, Asia Pacific Management Review 19(3) 215-238.

Winer, R. S. (2001). Customer relationship management: a framework, research directions, and the future. Haas School of Business

Zineldin, M. (2006). The royalty of loyalty: CRM, quality and retention. Journal of Consumer Marketing, 23(7), 430-437. https://doi.org/10.1108/07363760610712975. 